\title{
CONGRATULATION STRATEGIES OF JORDANIAN EFL POSTGRADUATE STUDENTS
}

\author{
Yasser Al-Shboul' \\ Ibrahim Fathi Huwari² \\ Salt College for Human Sciences, Balqa Applied University, Salt, Jordan' \\ Department of English Language and Literature, Zarqa University, Jordan ${ }^{2}$ \\ nowshboul@yahoo.com'
}

First received: 25 May 2016

Final proof received: 14 July 2016

\begin{abstract}
This study investigates congratulation strategies used by Jordanian EFL postgraduate students. It also investigates the types of positive politeness strategies in the congratulation speech act. Data were collected using an adopted version of discourse completion test (DCT) by Dastjerdi and Nasri (2013). Data were encoded and analyzed based on the taxonomy of congratulation strategy proposed by Elwood (2004). Furthermore, data were analyzed based on a modified version of positive politeness strategies proposed by Brown and Levinson (1987). Findings revealed that the most frequently used strategies of congratulation were illocutionary force indicating devise (IFID), offer of good wishes, and expression of happiness. Regarding the positive politeness strategies, findings revealed that the most frequently used strategies by the participants were giving gift to listener, exaggeration, and ingroup identity marker. The study concludes with a discussion of important directions for future research such as including more participants with different social background. The results are expected to be useful information in cross-cultural comparison studies and other related areas.
\end{abstract}

Keywords: speech act, DCT, congratulations, politeness strategies

Individuals living in a community interact with each other in their daily life, and this interaction is considered to be a complex phenomenon in the process of which not only external aspects like setting but also internal aspects such as the culture the interlocutors bring to the encounters play a major role in the realization of the communication (Byram \& Feng, 2005). Hence, friction between individuals is most likely to occur because of this interaction. In order to reduce friction and maintain peace and social harmony, each society has developed certain sets of rules that help people achieve verbal communication more smoothly. For example, many good things would happen to people such as graduating from university, getting promotion or getting engaged. In such situations, people feel compelled to express congratulations. Elwood (2004) indicates that it is common for people to express positive ideas and kind thoughts when something good happens to a person. It would be seen as a sign of jealousy if the other person who hears the good news does not show or express his/her pleasure on what has happened to the addressee. In a situation of happy news speakers mostly try to show their happiness by saying "congratulations", though, the patterns and expressions they use to express congratulations may vary in different situation. Moreover, MarkiTsilipakon (2001) stated that congratulation is the expression of speaker's joy and praise on a pleasurable event.
Based on Austin's classification of performative utterances that deal with attitudes and feelings, expressions including the verb 'congratulate' used in the first person singular present tense fall into the category of behabitives (Austin, 1962: 159). On the other hand, in Searle's classification of illocutionary acts, the expressions of congratulations are classified under the class of expressives, illocutionary acts whose 'illocutionary point is to express the psychological state specified in the sincerity condition about a state of affairs specified in the propositional content' (Searle, 1976, p. 12). Later, Searle set the following four rules that govern the act of congratulating: a) there is some event or act that is related to the hearer (propositional content rule); b) the event is in the hearer's interest and the speaker believes the event is in the hearer's interest (preparatory rule); c) the speaker is pleased at the event (sincerity rule); and d) it counts as an expression of pleasure at the event (Searle, 1969, p. 67). Searle and Vanderveken (1985) stated that the act of congratulating must be associated with the hearer, but need not involve an act or anything the hearer is responsible for. It could be merely 'some item of good fortune'. In contrast, Wierzbicka (1987) argues that the hearer must be, at least partly, responsible for the 'happy event'. She claims that it is impossible to congratulate a friend who has just received an inheritance without being ironic. She adds that the speaker performs the 
congratulating act because he wants to cause the hearer to know how he feels due to the good event.

From a politeness point of view, Leech (1983) classifies congratulation as convivial illocutionary function. This class involves acts in which the illocutionary goal coincides with the social goal. The act of congratulating, along with the acts of offering, inviting, greeting and thanking, is considered by Leech as intrinsically polite. By congratulating someone, the speaker adheres to the hearer's positive face (Leech, 1983, pp. 104-5). Consequently, research examining politeness strategies have focused on various speech acts such as apology (Blum-Kulka, House, \& Kasper, 1989; Bataineh \& Bataineh, 2006), refusal (Beebe et al., 1990; Al-Shboul, Maros, \& Yasin, 2012), request (Blum-Kulka \& House, 1989; Al-Momani, 2009), and advice (Hinkel, 1997; Chun, 2009; Al-Shboul \& Zarei, 2012). Those studies have contributed to showing the differences between NSs and NNSs and to better understanding of the use of appropriate linguistic forms in different languages and cultures and further to avoiding communication breakdowns. However, not many studies were conducted on the speech act of congratulation (Emery, 2000; MarkiTsilipako, 2001; Elwood, 2004; Allami \& Nekouzadeh, 2011; Dastjerdi \& Nasri, 2013), and in Jordanian context, to the researchers' best knowledge, there has been no study conducted on the speech act of congratulation among Jordanian EFL postgraduate students. Thus, it would be useful to examine how the speech act of congratulation is performed in English by Jordanian EFL postgraduate students at University Kebangsaan Malaysia (henceforth, UKM) that would contribute to cross-cultural comparison studies. In other words, this study aims to investigate the patterns and linguistic forms that Jordanian EFL postgraduate students use to offer congratulation in different situations. Furthermore, it investigates the types of positive politeness strategies which are frequently used by them in those situations. The reason for selecting English in the present study refers to the fact that English is the medium of instruction for Jordanian EFL learners in Malaysia and is also a language that is frequently needed in their everyday interaction. Therefore, it is important to pay attention to pragmatic competence of the Jordanian EFL learners rather than their grammatical competence.

\section{Literature Review}

A large body of literature has illustrated that while speech acts are universal, the realization of any given speech act varies greatly among cultures and languages. The speech act of congratulation has not been studied extensively with the exception of a few studies (Emery, 2000; Marki-Tsilipako, 2001; Elwood, 2004; Allami \& Nekouzadeh, 2011; Dastjerdi \& Nasri, 2013). The following paragraphs provide a brief overview of studies conducted on the speech act of congratulation in different cultural and linguistic speech communities.

In Greek context, Marki-Tsilipako (2001) discusses the differences between Greek "congratulation and "bravo." According to her, the less use of the expression "congratulation" is attributed to the assumption that the speaker belongs to the educated/urban class where the relationship between the interlocutors is not very close. For instance, those educated/urban people may use "congratulation" alongside with the expression of wishes such as "May that you live" or "an auspicious wedding" to express congratulation on the occasion of wedding. Additionally, they use the expressions such as "have a successful career" on the occasion of university graduation. On the occasion of job promotion, they make use of the term "to your next promotion". Hence, the expression "congratulation" in Greek context which shows the distance between the speakers and hearers, is used in official occasions and with hand shake, rather than an embrace or a kiss which represents the intimacy. The author further added that it would be inappropriate for the men to congratulate their mothers unless they are closely related. However, men only express congratulation to their fathers using the expressions such as: "Yatrabba fi'izzak wa ykuun wild saalitt" (may you raise him up to be a fine boy). Greek people also express congratulations in different occasions including New Year, returning from Hajj and the month of Ramadan. For example, they tend to use "haneetu bi-barakaat il- ed $n$ imtubil- ed" (congratulation on the blessing of the Eid) on the occasion of New Year. On the occasion of returning from Hajj the formulae "Hajj mabruur wa dhanb maghfuur wa tijaara laa tabuur" (congratulation on the Hajj and the visit) is the most commonly used expression. Finally, the expression "bi-shahr ramadaan-allaah yibaarak fiikum" (blessings on the advent of the holy month of Ramadan) is used as greeting in the holy month of Ramadan.

In a comparative study, Elwood (2004) investigates cross-cultural analysis of expressions of congratulations. The participants of this study were equally divided into three groups as: 45 American students writing in English, 45 Japanese students writing in English and 45 Japanese students writing in Japanese. Data were collected using a written discourse completion test (DCT). The DCT consisted of seven situations: three were related to reacting to good news such as grant, promotion and wedding. Results revealed different patterns in responding to good news among Americans and Japanese. In other words, while both group of Japanese tended to use self-related comments such as expression of envy, longing, chagrin or comment on one's future success, Americans were more likely to ask questions and request for information. 
In addition, results revealed that the "Illocutionary Force Indicating Device (IFID)" was the mostly used type of response in the situation of promotion, while in the situations of grant and wedding the "Expression of happiness" was the dominant type of response. Besides, the three participating groups mostly used the "Expression of validation" such as "you deserve it" in the situation of grant, whereas it was used only by Americans in the situation of wedding. Moreover, request for information such as "who's the lucky guy girl" was highly used by the three groups and mostly by the Americans in the situation of wedding. The other types of responses that were used by the groups in the three situations were: "Offer of good wishes", "A suggestion to celebrate", "Offer of good luck" and "Encouragement". Elwood's (2004) study is particularly important because of her proposed taxonomy for the congratulation strategies which was used as the framework for the present study.

In Iranian context, Allami and Nekouzadeh (2011) examine the realization of the speech act of congratulation by Iranian Persian speakers. The participants of the study were 50 males and females with the age range of 17-75 with different socioeconomic backgrounds. Data were collected using a written discourse completion test (DCT). The DCT consisted of seven situations related to good news. Next, data were analyzed based on the modified version of Brown and Levinson's model of politeness (1987), it further explored the positive politeness strategies in the congratulation speech act. Results revealed that the most frequently used strategies of congratulation were "Illocutionary Force Indicating Devise (IFID)", “Offer of good wishes" and "Expression of happiness". Moreover, the analysis of the positive politeness strategies data confirmed the fact that Iranian people frequently made use of the strategies "Giving gift to listener", "Exaggeration" and "In-group identity marker" when responding to other's happy news.

In another comparative study, Dastjerdi and Nasri (2013) investigate the cross-cultural differences in the production of the speech act of congratulation. The participants of this study were divided into three groups as: 48 American native speakers, 50 Persian native speakers and 44 native speakers of Syrian Arabic. Data were collected using a written discourse completion test (DCT). The DCT consisted of four situations on each of which the participants were asked to offer congratulations. Data were analyzed based on the frequencies of each strategy, content of semantic formulas and the participants shift according to the status of the hearer. Results revealed that the most frequently used strategy by the three participating groups was IFID. They tended to use it in more than $60 \%$ of the situations. The second most frequent formula for both groups of Syrian Arabic and Persian speakers was that offer of good wishes but it was the request for information for the Americans. In terms of differences, the main difference among the three participating groups was that of offer of wishes which the Arabs used the most and the Americans the least. The DCT proposed by Dastjerdi and Nasri (2013) was adopted for the present study, and the findings of the present study will be compared to findings from Dastjerdi and Nasri's (2013) study.

In Arabic context, Emery (2000) investigates the politeness formulas of greeting, congratulation and commiserating in Omani Arabic. However, the researcher examines only the congratulation expressions made by old and young people on different occasions. Data were collected through questionnaire and introspection by native speakers. Based on these data the researcher overviews the linguistic rituals and discourse structures and shows how formulas can be used linguistically in different ways by various groups (e.g., age, gender groups). Data were analyzed based on the classification system of the politeness formulas proposed by Tannen and Öztek (1981). This classification system involves the categories rapport-establishment, happy events and anxiety-provoking events and analyses congratulating within the category of "happy events" which is further divided into two groups as "occasions" and "gains" (Tannen \& Öztek, 1981). Nonetheless, the researcher specifically focuses with "occasions" (for either public or private joy) in his examination of congratulation and therefore, focuses on weddings, birth of a 32 baby and festive congratulations (e.g., beginning of Ramadan, people returning from Hajj).

To sum up, it can be seen that the speech act of congratulation may vary from culture to culture. It also can be seen from the literature that this speech act has not been studied adequately in Arabic culture. Specifically, to the researchers' best knowledge, there has been no investigation of the speech act of congratulation conducted on Jordanian EFL learners. Therefore, it would be useful to examine how the speech act of congratulation is performed in English by Jordanian EFL postgraduate students at UKM that would contribute in cross-cultural comparisons. This will be the gap where the contribution will be made by this study.

\section{The Study}

This study aims to investigate the patterns and linguistic forms that Jordanian EFL postgraduate students use to offer congratulation on the occasions related to marriage and birth of a baby. It also aims to investigate the types of positive politeness strategies which are frequently used by them in those situations. It is mainly based on Brown and Levinson's (1987) theory of politeness which has influenced most of the theoretical and analytical works related to politeness. They based their theory on Goffman's (1967) notion of face. According to 
them, there are two aspects of people's feelings involved with face in the process of communication and interaction. These two aspects are positive face and negative face. On one hand, the positive face is the desire of the individual "to be liked of /approved of." Negative face, on the other hand, is the desire of the individual "not to be imposed on." A facethreatening act tends to risk either the speaker's (S) or the hearer's $(\mathrm{H})$ positive or negative face. For example, speech acts such as requests, orders, promises, etc. are most likely to threat H's negative face whereas refusals, criticism, etc. are likely to threat H's positive face; while S's negative face tends to be threatened by act such as making excuse, S's positive face tends to be threatened by act such as apology (Brown \& Levinson, 1987). The speech act of congratulation is oriented towards the positive face needs of the addressee and therefore can be perceived as a positive politeness strategy. Brown and Levinson (1987) stated that the linguistic realizations of positive politeness are considered to be representative of the normal linguistic behaviour between intimates. They are used, as they explained, 'as a kind of metaphorical extension of intimacy' or 'as a kind of social accelerator where S [a speaker], in using them, indicates that he wants to 'come closer' to H (a hearer)' (Brown \& Levinson, 1987, p. 101). Once again, the present study aims to investigate the types of positive politeness which are frequently used by Jordanian EFL postgraduate students in different situations. Therefore these emerging two research questions that initiated this study:

1) What are the main strategies and substrategies used by Jordanian EFL postgraduate students to express congratulation?

2) What types of positive politeness strategies are more frequent in the congratulations of Jordanian EFL postgraduate students?

\section{METHOD}

\section{Participants}

The participants to the present study were thirty Jordanian EFL learners (JEFL). The participants were all postgraduate students, both Masters and $\mathrm{PhD}$, pursuing studies in both pure sciences and applied sciences at UKM's main campus located in Bandar Baru Bangi, a town in the state of Selangor, Malaysia. They also are relatively homogeneous in terms of their cultural background (Jordanian Arabs of northern region of Jordan) and academic/linguistic experiences (30- to 40 year old postgraduates, both master and $\mathrm{PhD}$, pursuing studies in both pure science and applied science fields at UKM). All 38 JEFL of northern region of Jordan who are pursuing studies in both pure science and applied science fields at UKM participated in the study. However, responses of only 30 male students whose ages ranged from 30 40 were returned to the researchers and 8 questionnaires were not returned to them. Thus, 30 male native speakers of Jordanian Arabic whose parents are also native speakers of Jordanian Arabic participated in this study. In addition, all of them had never travelled to any English speaking countries other than to and within Malaysia. Finally, some of the participants have TOEFL or IELTS and some of them passed the English Placement Test at UKM. Hence proficiency was determined based on their scores of the institutional TOEFL, IELTS, or English Placement Test scores, and therefore were judged to represent intermediate English proficiency.

\section{Instrument and Procedure}

The issue of how data are collected is one of the main concerns in cross-cultural researches. Trosborg (1995) stressed that data collection in an ethnographic procedure (i.e. naturally occurring data) is the ultimate goal in most cross-cultural researches. This data collection method is considered to be the most reliable data source in speech act research because it reflects what speakers actually say rather than what they think they will say in a given speech situation (Wolfson, 1986; Bardovi-Harlig \& Hartford, 1993). However, the contextual variables (e.g., gender, age, status) are difficult to be controlled and very time consuming. Another limitation is that the occurrence of some speech acts cannot be predicted and therefore this method might not yield enough instances of a particular speech act. Accordingly, collecting ethnographic data seem to be an unlikely option for cross-cultural speech act researches. As a result, due to the limitations of those of ethnographic procedures, the present study adopted a written discourse completion test (DCT) established by Dastjerdi and Nasri (2013) as the data collection procedure (see Appendix A). In their distinction between DCT and MCQ, Kasper and Dahl (1991) pointed out that the difference between DCT and MCQ data lies in the type of elicited responses, i.e. MCQ elicits 'perceptions of alternative speech act realization', while DCT is classified to constrained production instrument.

That is, an adopted version of Dastjerdi and Nasri's (2013) DCT was chosen to investigate the patterns and linguistic forms that Jordanian EFL postgraduate students use to offer congratulation in different situations. Two different variables were manipulated to represent the relationship between the speaker and the hearer in the situations: social status (high-low, low-high, equal) and social distance (close, middle status, distance). Closeness was represented by the relationship between friends (situation 1), distant relationship by participants who do not know each other (situation 4), and a middle status of social distance was represented by 
acquaintances (situations 2 and 3). Power was also represented by three levels: high-low, that is the speaker has power over the hearer (situation 3), lowhigh, i.e. the hearer has power over the speaker (situation 2), and equal, i.e. no participant has power over the other (situations 1 and 4). The researchers met the participants and administered the questionnaires at five computer laboratories from 3 faculties/institutes, namely the Faculty of Information Science and Technology, the Institute of Bioscience and Biotechnology Studies, and the Institute of Mathematical Science Studies. The details of the administration are as the following:

1. The researchers explained the instruction of the questionnaire in participants' native language (Arabic) in order to make sure that they were aware of the task.

2. Participants were then asked to read each situation and react to it by trying to place themselves into the situations presented. They were asked to offer congratulation as they would in actual conversation.

Data collected via the DCT were analyzed by using semantic formulas as units of analysis. This method of analysis was also used in other speech act studies such as Beebe and Cummings (1985) and Beebe et al. (1990). In the present study, data of congratulation expressions were encoded and analyzed based on the taxonomy of congratulation strategy proposed by Elwood (2004) (see Appendix $\mathrm{B})$, and further they were analyzed according to the classification of positive politeness strategies proposed by Brown and Levinson (1987). A semantic formula refers to "a word, phrase, or sentence that meets a particular semantic criterion or strategy, any one or more of these can be used to perform the act in question" (Cohen 1996, p. 265). For example, in the situation where respondents had to offer congratulation to a friend getting married, a congratulation responses such as "Congratulation my dear friend, I am so glad to hear that and wish you the best of luck in your new life," was analyzed as consisting of three units, each of which falls into a corresponding semantic formula (as shown in the brackets):

- Congratulation my dear friend [IFID].

- I am so glad to hear that [Expression of happiness].

- Wish you the best of luck in your new life

[An offer of good wishes].

The initial analysis of the data was run by the researchers of this study. In order to achieve the reliability of data analysis, the researchers invited two independent raters in order to make sure that the strategies matched the data in light of the classification established by Elwood (2004) and
Brown and Levinson (1987). Both of the independent raters were postgraduate students majoring in linguistics and are well-trained in the analysis of speech acts coding schema. There were found some differences in the coding schema, therefore a discussion was held and adjustments were made, based on consensus. It is important to indicate that there was a minor modification on the classification of positive politeness strategies proposed by Brown and Levinson. This modification was made in order to capture salient strategies used in the present study (see Appendix C).

\section{RESULTS AND DISCUSSION}

As shown in Table 1 below, all written congratulation responses obtained from the participants resulted in 289 English congratulation strategies. IFID (e.g., "Congratulations.") was the most frequent strategy used by the participants in approximately $37.7 \%$ of the strategies $(n=109)$. An offer of good wishes (e.g., "Wish you the best of luck in your new life") was the second most frequent strategy mentioned by the participants in approximately $26.3 \%$ of the strategies $(n=76)$. Expression of happiness (e.g., "I am so glad to hear that".) was the third most frequent strategy mentioned by the participants in approximately $13.1 \%$ of the strategies $(n=38)$. As the fourth most frequently used strategy, the participants used request for information (e.g., "Is your new baby a boy or a girl?") in approximately $8.0 \%$ of the strategies $(\mathrm{n}=23)$. Ask for sweets (e.g., "You must bring me some sweet".) was the fifth most frequent strategy mentioned by the participants in approximately $6.2 \%$ of the strategies $(n=18)$. The participants used self-related comments (e.g., "May God give me a cute baby as yours".) as the sixth most frequent strategy in approximately $4.8 \%$ of the strategies $(\mathrm{n}=14)$. Using Joke (e.g., "You better if you didn't get married".) was seen as the least frequent strategy among others, at $3.8 \%$ of the responses $(n=11)$.

Consequently, similar results where the speech act of congratulation is concerned were found when compared to studies done by Elwood (2004), Allami and Nekouzadeh (2011), and Dastjerdi and Nasri (2013). For example, Allami and Nekouzadeh (2011) found that the most frequently used strategies of congratulation were "Illocutionary Force Indicating Devise (IFID)", "Offer of good wishes" and "Expression of happiness." Unlike Elwood's (2004) study, the participants of the present study had asked their interlocutors to give them some sweets. This particular semantic formula reflects a deeply rooted cultural value. This is in accordance with Dastjerdi and Nasri (2013) who found that both groups of Arab and Persian participants had asked the hearer to give him/her some sweets. The researchers attributed that to their culture in that 
when something good happens, such as marriage or birth of a child, etc., they distribute some sweets among their friends or relatives. When the semantic formula an offer of good wishes is concerned, the participants were more sensitive to the status level of the hearer. More specifically, they used more good wishes for the lower status hearer as is the case with situation number three. This is also in accordance with Dastjerdi and Nasri (2013) who found that Syrian Arabic used more good wishes for the lower status hearer.

Table 1. Frequency of semantic formulas used in DCT situations

\begin{tabular}{|c|c|c|c|c|c|c|c|c|c|c|c|c|c|c|c|c|}
\hline \multirow{3}{*}{ Situations } & \multicolumn{14}{|c|}{ Strategies } & \multirow{2}{*}{\multicolumn{2}{|c|}{ Total }} \\
\hline & \multicolumn{2}{|c|}{ IFID } & \multicolumn{2}{|c|}{$\begin{array}{l}\text { Expression } \\
\text { of } \\
\text { happiness }\end{array}$} & \multicolumn{2}{|c|}{$\begin{array}{l}\text { An offer of } \\
\text { good wish }\end{array}$} & \multicolumn{2}{|c|}{$\begin{array}{l}\text { Request for } \\
\text { information }\end{array}$} & \multicolumn{2}{|c|}{$\begin{array}{l}\text { Ask for } \\
\text { Sweets }\end{array}$} & \multicolumn{2}{|c|}{$\begin{array}{c}\text { Self- } \\
\text { related } \\
\text { comments }\end{array}$} & \multicolumn{2}{|c|}{ Joke } & & \\
\hline & No & $\%$ & No & $\%$ & No & $\%$ & No & $\%$ & No & $\%$ & No & $\%$ & No & $\%$ & No & $\%$ \\
\hline 1 & 29 & 10.0 & 6 & 2.0 & 17 & 5.9 & 11 & 3.8 & 7 & 2.4 & 9 & 3.1 & 7 & 2.4 & 86 & 29.6 \\
\hline 2 & 30 & 10.4 & 15 & 5.2 & 14 & 4.8 & 0 & 0.0 & 0 & 0.0 & 0 & 0 & 0.0 & 0.0 & 59 & 20.4 \\
\hline 3 & 24 & 8.3 & 9 & 3.1 & 24 & 8.3 & 8 & 2.8 & 11 & 3.8 & 5 & 1.7 & 4 & 1.4 & 85 & 29.4 \\
\hline 4 & 26 & 9.0 & 8 & 2.8 & 21 & 7.3 & 4 & 1.4 & 0 & 0.0 & 0 & 0 & 0.0 & 0.0 & 59 & 20.5 \\
\hline Total & 109 & 37.7 & 38 & 13.1 & 76 & 26.3 & 23 & 8.0 & 18 & 6.2 & 14 & 4.8 & 11 & 3.8 & 289 & 99.9 \\
\hline
\end{tabular}

Regarding the positive politeness strategies, the participants used semantic formulas that can be classified as positive politeness strategies. In other words, the participants used 237 semantic formulas that can be classified as positive politeness strategies (see Table 2). Give gift to the listener (e.g., "Congratulations.") was the most frequent strategy used by the participants in approximately $55.2 \%$ of the strategies $(\mathrm{n}=131)$. Exaggerate (e.g., "Wow, that's great") was the second most frequent strategy mentioned by the participants in approximately $25.3 \%$ of the strategies $(n=60)$. Use of in-group identity marker (e.g., "My dear friend".) was the third most frequent strategy mentioned by the participants in approximately $7.1 \%$ of the strategies $(n=17)$. As the fourth most frequently used strategy, the participants used joke (e.g., "You should have a second wife soon") in approximately $4.7 \%$ of the strategies $(\mathrm{n}=11)$. Give or ask for reason (e.g., "Why you didn't invite me for your wedding!?") was the fifth most frequent strategy mentioned by the participants in approximately $4.2 \%$ of the strategies $\quad(\mathrm{n}=10) . \quad$ Seek agreement (e.g., "Congratulations, but don't have a big family".) was seen as the least frequent strategy among others, at $3.4 \%$ of the responses $(n=8)$.

Table 2. Frequency of positive politeness strategies used in DCT situations

\begin{tabular}{|c|c|c|c|c|c|c|c|c|c|c|c|c|c|c|}
\hline \multirow{3}{*}{ Situations } & \multicolumn{12}{|c|}{ Positive Politeness Strategies } & \multirow{2}{*}{\multicolumn{2}{|c|}{ Total }} \\
\hline & \multicolumn{2}{|c|}{ Exaggerate } & \multicolumn{2}{|c|}{$\begin{array}{c}\text { In-group } \\
\text { identity } \\
\text { marker }\end{array}$} & \multicolumn{2}{|c|}{$\begin{array}{c}\text { Seek } \\
\text { agreement }\end{array}$} & \multicolumn{2}{|c|}{ Joke } & \multicolumn{2}{|c|}{$\begin{array}{l}\text { Give or ask } \\
\text { for reason }\end{array}$} & \multicolumn{2}{|c|}{$\begin{array}{l}\text { Give gifts } \\
\text { to the } \\
\text { listener }\end{array}$} & & \\
\hline & No & $\%$ & No & $\%$ & No & $\%$ & No & $\%$ & No & $\%$ & No & $\%$ & No & $\%$ \\
\hline 1 & 20 & 8.4 & 11 & 4.6 & 3 & 1.3 & 7 & 3.0 & 8 & 3.4 & 37 & 15.6 & 86 & 36.3 \\
\hline 2 & 17 & 7.2 & 4 & 1.7 & 0 & 0.0 & 0 & 0.0 & 0 & 0.0 & 35 & 14.8 & 56 & 23.7 \\
\hline 3 & 14 & 5.9 & 0 & 0.0 & 5 & 2.1 & 4 & 1.7 & 2 & .84 & 28 & 11.8 & 53 & 22.3 \\
\hline 4 & 9 & 3.8 & 2 & 0.84 & 0 & 0.0 & 0 & 0.0 & 0 & 0.0 & 31 & 13.0 & 42 & 17.6 \\
\hline Total & 60 & 25.3 & 17 & 7.1 & 8 & 3.4 & 11 & 4.7 & 10 & 4.2 & 131 & 55.2 & 237 & 99.9 \\
\hline
\end{tabular}

Accordingly, the participants' use of positive politeness strategies would be perceived as an attempt to save the positive face needs of the addressee. This is in accordance with Brown and Levinson (1987) who stated that the speech act of congratulation is oriented towards the positive face needs of the addressee and therefore can be perceived as a positive politeness strategy. Moreover, results on positive politeness strategies concur with the study on Iranian Persian congratulations by Allami and Nekouzadeh (2011) who found that the most frequently used strategies were "Giving gifts to the listener" (50\%) such as "mobārcek bāše" (congratulation) or "äfarin" (welldone) and "Exaggeration" (18.8\%) such as "āliye" (great). In addition, the participants' use of in-group identity marker (e.g., "My dear friend".) as the third most frequent strategy reflects a deeply rooted cultural value. This is in accordance with Al-Shboul (2014) in his study on the speech act of refusal. He found that while both groups of Jordanians used the semantic formulas of define relationship (e.g., "My dear professor"), there were no occurrences of this semantic formula in the responses given by American participants. The researcher attributed that as a reflection of a native Arab cultural norm. Arabs are classified to be more rank-conscious than westerners. This confirmed in their attempts to emphasize and even overstress their recognition of 
the higher social rank of their interlocutors (Hamady, 1960).

Hence, Arabs communication style of emphasizing the rank of a higher social status is a way to be more polite and show higher degree of respect to their interlocutors. Finally, Brown and Levinson (1978) stated that using in-group address terms such as calling the person of his/her first name and employing endearments (e.g., honey, dear, darling, sir, buddy) is to emphasize the solidarity and friendliness between the speaker and the hearer.

\section{LIMITATIONS AND FURTHER RESEARCH}

While this study has generally answered the proposed research questions, further research on the speech act of congratulation by Jordanians need to be investigated. The generalizability of findings may be constrained by the following considerations.

Firstly, the sample size only involved a small number of participants who were all male postgraduate students pursuing studies in both pure science and applied science fields. Therefore, future studies should include more participants involving female participants, larger/bigger participants, and different social groups. Because of the size of the current research, the generalizability of this study should not be assumed. Secondly, collecting data using one instrument is not enough to provide insights into every aspect of the Jordanian congratulation strategies. According to Rose and Ono (1995), "we should not expect a single data source to provide all the necessary insights into speech act usage" (p. 207).

Moreover, researches done on the data collection methods used in speech act studies also reported the limitations of the DCT as compared to the data obtained from natural settings. For example, Yuan (2001) observed that the DCT responses are shorter, simpler, less face-attentive and less emotional. Therefore, collecting natural data would be more reliable, for what one claims one will do in a given situation is not necessarily what one actually does in a real life situation. Another methodological drawback of this study, like any similar study, was that some variables such as age and gender were not examined. Therefore, such variables need to be investigated to see their influences on speech behaviours in congratulations. What is more, future researchers are encouraged to be aware of the pragmatic and the grammatical appropriateness of the participants' utterances, since the present study neither examined the pragmatic nor the grammatical appropriateness of the participants' utterances. They are also encouraged to conduct more researches on the congratulation strategies used by other cultures and ethnic groups for the purpose of prompting cultural understanding which would help reduce misunderstandings caused by the misuse of the speech act of congratulation among people from different cultures and ethnic groups. For example, investigating the similarities and differences in the speech act of congratulation by American English and Jordanian Arabic.

\section{CONCLUSION}

The present study has contributed to our understanding of how the speech act of congratulation is performed in English by Jordanian EFL postgraduate students. It also has been shown that speech acts reflect the cultural norms and values that are possessed by speakers of different cultural backgrounds, as different cultures are very likely to realize speech acts quite differently. Such differences might cause misunderstanding or communication breakdowns when people from different cultural backgrounds come in contact with each other. Finally, the presents study has revealed important findings that would be useful in studies in intercultural comparisons and other related areas.

\section{REFERENCES}

Allami, H., \& Nekouzadeh, M. (2011). Congratulation and positive politeness strategies in Iranian context. Theory and Practice in Language Studies, 1(11), 16071613

Al-Momani, H. S. (2009). Caught between two cultures: The realization of requests by Jordanian EFL learners. $\mathrm{PhD}$ dissertation. Indiana University of Pennsylvania, USA.

Al-Shboul, Y. (2014). Pragmatic transfer of refusal strategies in English among Jordanian EFL learners at UKM. Unpublished doctoral dissertation, University Kebangsaan Malaysia, Bangi, Malaysia.

Al-Shboul, Y. Maros, M. \& Yasin, M.S.M. (2012). An intercultural study of refusal strategies in English between Jordanian EFL and Malay ESL postgraduate students. $3 L$ The Southeast Asian Journal of English Language Studies, 18(3), 29-39.

Al-Shboul, Y. Zarei, N. (2012). Gender differences in the appropriateness of advice-giving among Iranian EFL learners. International Journal of Language Learning and Applied Linguistics World, 3(4), 88-98.

Austin, J. (1962). How to do things with words. Oxford: Clarendon press.

Bardovi-Harlig, K., \& Hartford, B. S. (1993). Refining the DCT: Comparing open questionnaires and dialogue completion tasks [Monograph]. Pragmatics and Language Learning, (4), 143-165.

Bataineh, R. F. \& Bataineh, R. F. (2006). Apology strategies of Jordanian EFL university students. Journal of Pragmatics, (38), 19011927. 
Beebe, L. M. \& Cummings, M. C. (1985). Speech act performance: A function of the data collection procedure. Paper presented at the Nineteenth Annual TESOL Conference, New York.

Beebe, L.M. Takahashi, T. \& Uliss-Weltz, R. 1990. Pragmatic transfer in ESL refusals. In R. C. Scarcella, E. S. Anderson, and S. D. Krashen (Eds.), Developing communicative competence in a second language (pp. 55-94). New York: Newburry House.

Blum-Kulka, S. \& House, J. (1989). Cross-cultural and situational variation in requesting behavior. In S. Blum-Kulka, J. House, \& G. Kasper (Eds.), Cross-cultural pragmatics: Requests and apologies (pp. 123-154). Norwood, NJ: Ablex.

Blum-Kulka, S., House, J., \& Kasper, G. (1989). Cross-cultural pragmatics: Requests and apologies. Norwood, NJ: Ablex.

Brown, P. \& Levinson S. (1978). Universals in language usage: Politeness phenomena. In Esther N. Goody (ed.) Questions and politeness, (pp. 56-289). Cambridge: Cambridge University Press.

Brown, P. \& Levinson S. (1987). Politeness: Some universals in language usage. Cambridge: Cambridge University Press.

Byram, M. \& Feng, A. (2005). Teaching and researching intercultural competence. In E. Hinkel (Ed.), Handbook of research in second language teaching and learning (pp. 911-930). Mahwah, NJ: Lawrence Erlbaum Associates.

Chun, M. Y. (2009). Cultural relativity and universality of linguistic politeness: the speech act of advice. Unpublished doctoral dissertation. Korea University, Korea.

Cohen, A. (1996). Speech act. In S. L. Mckay, \& N. H. Horeberger (Eds.). Sociolinguistics and language teaching (pp. 393-420). Cambridge: Cambridge University Press.

Dastrjerdi, H. V. and Nasri. N. (2013). 'A crosscultural study of speech acts: situational aspects of congratulations in English, Persian and Arabic', Global Journal of Foreign Language Teaching, (1), 15-22.

Elwood, K. (2004). ““Congratulations!”: A crosscultural analysis of responses to another's happy news'. The Cultural Review, Waseda Commercial Studies Association, (25),
355-386.

Emery, P. G. (2000). Greeting, congratulating and commiserating in Omani Arabic. Language, Culture and Curriculum, 13(2), 196-217.

Goffman, E. (1967). Interaction ritual. New York: Anchor.

Hamady, S. (1960). Temperament and characters of the Arab. New York: Twayne Publishers.

Hinkel, E. (1997). Appropriateness of advice: DCT and multiple choice data. Applied Linguistics, 18(1), 1-26.

Kasper, G., \& Dahl, M. (1991). Research methods in interlanguage pragmatics. Studies in Second Language Acquisition, 13(2), 215-247.

Leech, G. (1983). Principles of pragmatics. London: Addison-Wesley

Makri-Tsilpakou, M. (2001). Congratulations and Bravo! In A. Bayraktaroglu \& M. Sifianou (Eds.) Linguistic politeness across boundaries: The case of Greek and Turkish (pp. 137-176). Athens: John Benjamin Publishing Company.

Rose, K. R., \& Ono, R. (1995). Eliciting speech act data in Japanese: The effect of questionnaire type. Language Learning. 45(2), 191-223.

Searle, J. \& Vanderveken, D. (1985). Foundations of illocutionary logic. Cambridge: Cambridge University Press.

Searle, J. (1969). Speech acts: An essay in the philosophy of language. Cambridge, England: Cambridge University Press.

Searle, J. (1976). A classification of illocutionary acts. Language in Society 5(1), 1-23

Tannen, D. \& Oztek, P. (1981). "Health to our mouths ${ }^{\text {ee }}$ : Formulaic expression in Turkish and Greek. In F. Coulmas (Ed.), Conversational routine (pp. 37-54). The Hague: Mouton.

Trosborg, A. (1995). Interlanguage pragmatics. Requests, complaints and apologies. Berlin: Mouton de Gruyter.

Wierzbicka, A. (1987). English speech act verbs: A semantic dictionary. Sydney: Academic Press.

Wolfson, N. (1986). Research methodology and the question of validity. TESOL Quarterly 20(4) 689-699.

Yuan, Y. (2001). An inquiry into empirical pragmatics data-gathering methods: written DCTs, oral DCTs, field notes, and natural conversations. Journal of Pragmatics. 33(2) 271-292. 


\section{APPENDIX A}

DISCOURSE COMPLETION TEST (DCT) ADOPTED FROM DASTJERDI AND NASRI (2013)

Instruction: Please read the following situations. After each situation you will be asked to write a response in the blank in order to congratulate a person. Please respond as naturally as possible and try to write your response as you feel you would say it in the situation. The data will be used for research purposes only.

1- While waiting in the bus stop, you see one of your friends. It's a long time you haven't seen him/her.

You: hey, how are you? How is everything with you?

Your friend: Well, my big news is that I got married three months ago.

You:.

2- You are an employee in a company and you have been informed that your employer got married recently. At noon, you see your employer and you want to congratulate him/her.

You say:.

3- You are a clerk. You see the janitor of the office.

You: you weren't at work for a few days. What's up?

Janitor: Well, my child was born three days ago!

You say:.

4- You work in a company. While working in your office Mr. X with whom you are not intimate enters and wants to speak with your colleague at the same office. Your colleague says: Mr. X's child was born yesterday.

You say to Mr.X:

Thanks for your time and effort

\section{APPENDIX B}

CLASSIFICATION OF CONGRATULATION STRATEGIES BY ELWOOD (2004)

1- Illocutionary force indicating device (IFID) (e.g., "Congratulation")

2- Expression of happiness

a. Expression of personal happiness (e.g., "I am so glad")

b. Statements assessing the situation positively (e.g., "That's great")

3- An offer of good wishes (e.g., "I wish you the best of luck in your new life")

4- Request for information (e.g., "Is your new baby a boy or a girl?")

5- Asking for sweets (e.g., "You must bring me some sweet")

6- Self-related comments: an expression of envy and longing (e.g., "May God give me a cute baby as yours")

7- Joke (e.g., "You better if you didn't get married")

\section{APPENDIX C:}

\section{A MODIFIED VERSION OF POSITIVE POLITENESS STRATEGIE PROPOSED BY BROWN AND}

\section{LEVINSON (1987)}

1- Exaggerate (interest, approval, sympathy with the listener) (e.g., "Wow, that's great")

2- Use of in-group identity marker

a- Usage of address forms (e.g., "My dear friend")

b- Use of in-group language (e.g., "Well-done")

3- Seek agreement

a- Safe topic (e.g., "Congratulations, but don't have a big family")

4- Give or ask for reason (e.g., "Why you didn't invite me for your wedding!?”)

5- Give gifts to the listener (goods, sympathy, understanding) (e.g., "Congratulations.") 